\title{
Testing the criticality of HR-TQM factors in the Malaysian higher education context.
}

\begin{abstract}
The aim of this paper is to provide evidence on the degree of criticality and reliability tests for human resource (HR) related critical success factors (CSFs) in TQM implementation. This involves identifying and defining the HR-related CSFs from an exhaustive source of literature reviews on quality initiatives. In higher education (HE) contexts, the CSFs in TQM programmes emphasise more management commitment, HR management and quality working attitudes for customer satisfaction. Therefore, the 'soft' or HR aspects in the literature review stand as the fundamental issue of concern for organizational management in quality planning and creating a quality working climate to ensure successful expected performance. Using Statistical Package for Social Sciences (SPSS), the HR-related CSFs that have high mean scores and reliability coefficients, are teamwork spirit, competent staff, customer-focus orientation and visionary leadership. Other factors have reasonably high scores and are recommended to be included in similar research in contexts other than simply the HE context.
\end{abstract}

Keyword: TQM; Human Resource Management; Critical success factors; Service quality; Reliability; Higher education. 